\title{
REFERENCE SITUATION IN POLITICAL PR-DISCOURSE: SPECIFICITY OF THE CONSTRUCTION
}

\author{
Evgeniya A. Frolova \\ Irkutsk State University, Irkutsk, Russia
}

\begin{abstract}
The article analyzes the process of discursive construction of the worldview which leads to a change in the characteristics of political discourse and its transformation into political public relations discourse, namely to the transition from socially important referents to those that are personally relevant. Based on the modern understanding of the social phenomenon of public relations activity the author gives a definition of political public relations discourse; it is proven that the main principle which allows distinguishing political public relations discourse from political discourse is the construction of the referent situation by a politician. Linguistic analysis of English political public relations discourse (a fragment of B. Obama's speech made during the election campaign in 2012) shows how the referent situation is constructed so as to discursivize certain personal (positive) qualities of the politician and to carry out a strategy of self-presentation; the politician's image and reputation as well as the political party he represents become the main themes and referents of his political public relations discourse. It is concluded that in political public relations discourse a version of reality is constructed which is favourable for the politician and which he then uses in order to create another, possible world, represented as a desirable world in discourse.
\end{abstract}

Key words: hybrid discourse, PR-discourse, political PR-discourse, discursive construction, referent, reference situation, image, strategy of self-presentation.

Citation. Frolova E.A. Reference Situation in Political PR-Discourse: Specificity of the Construction. Vestnik Volgogradskogo gosudarstvennogo universiteta. Seriya 2, Yazykoznanie [Science Journal of Volgograd State University. Linguistics], 2017, vol. 16, no. 4, pp. 193-200. (in Russian). DOI: https://doi.org/10.15688/jvolsu2.2017.4.18

\section{РЕФЕРЕНТНАЯ СИТУАЦИЯ В ПОЛИТИЧЕСКОМ ПИАР-ДИСКУРСЕ: ОСОБЕННОСТИ КОНСТРУИРОВАНИЯ}

\author{
Евгения Александровна Фролова \\ Иркутский государственный университет, г. Иркутск, Россия
}

\begin{abstract}
Аннотация. В статье анализируется процесс дискурсивного конструирования картины мира, которое приводит к изменению характеристик политического дискурса и трансформации его в политический пиар-дискурс, а именно к переходу от общественно значимых референтов к персонально значимым. С опорой на современное понимание социального феномена пиар-деятельности дано авторское определение понятия политического пиар-дискурса и доказано, что главным принципом, позволяю— щим отграничить политический пиар-дискурс от собственно политического дискурса, является конструирование политиком референтной ситуации. В результате лингвистического анализа англоязычного политического пиар-дискурса (фрагмента выступления Б. Обамы в рамках предвыборной кампании 2012 г.) показано, как референтная ситуация в нем конструируется таким образом, что дискурсивизиру๗̈. ются те или иные (положительные) личностные качества политика и осуществляется стратегия самопрезентации, главными референтами и темами политического пиар-дискурса становятся имидж и репेтация политика, а также политической партии, которую он представляет. Обоснован вывод о том, что () в политическом пиар-дискурсе конструируется такая версия реальности, которая выгодна политику и
\end{abstract}


которая затем используется им для создания другого, возможного мира, представляемого в дискурсе как мир желаемый.

Ключевые слова: гибридный дискурс, пиар-дискурс, политический пиар-дискурс, дискурсивное конструирование, референт, референтная ситуация, имидж, стратегия самопрезентации.

Цитирование. Фролова Е. А. Референтная ситуация в политическом пиар-дискурсе: особенности конструирования // Вестник Волгоградского государственного университета. Серия 2, Языкознание. - 2017. T. 16, № 4. - C. 193-200. - DOI: https://doi.org/10.15688/jvolsu2.2017.4.18

1

Целью данной статьи является исследование гибридного политического дискурса, а именно политического пиар-дискурса, и проверка гипотезы о том, что главным принципом, позволяющим отграничить политический пиар-дискурс от собственно политического дискурса, является конструирование политиком референтной ситуации, что, в свою очередь, ведет к конструированию положительного имиджа политика в глазах социального адресата и переводит политический дискурс в статус пиар-дискурса.

В настоящее время интерес исследователей к проблеме изучения проникающих друг в друга дискурсов, смешанных по своему содержанию, все более возрастает. Так, Е.И. Шейгал отмечает, что «вследствие прозрачности границ дискурса нередко происходит наложение характеристик разных видов дискурса в одном тексте» [Шейгал, 2000, с. 24]. С.Н. Плотникова, выделяя комический дискурс, останавливается на проблеме восприятия его как единого целого или же как части, инкорпорированной в дискурс другого типа. Комический дискурс может функционировать в виде отдельного самостоятельного жанра частного дискурса (анекдот, шутка, дружеское подтрунивание, издевка и т. п.), но в то же время комический дискурс легко инкорпорируется практически в любой другой дискурс: бытовой, массмедийный, политический, научный, неискренний и т. д. [Плотникова, 2003]. Н.Н. Панченко выделяет конвергентный дискурс, под которым она понимает инкорпорирование дискурсом одного типа дискурса другого типа и сближение этих дискурсов, ведущее к возникновению неких общих структурных свойств в рамках единого целого [Панченко, 2011].

В своем исследовании мы принимаем термин «гибридный дискурс», предлагаемый
О.К. Ирисхановой. Такой дискурс определяется как наложение двух типов дискурса друг на друга, при этом каждый из них модифицирует и дополняет специфические черты другого. Принимая термин «гибридный дискурс», мы, вслед за О.К. Ирисхановой, включаем подобный дискурс в более общий когнитивный феномен гибридизации - «универсальной когнитивной способности человека, направленной на творческое освоение мира» и проявляющейся в «способности порождать ментальные пространства-бленды» [Ирисханова, 2011, с. 63].

На современном этапе лингвистических исследований политический дискурс уже достаточно хорошо изучен в трудах отечественных и зарубежных лингвистов [Плотникова, 2004; 2005; Чудинов, 2006; Шейгал, 2000; Chilton, Schaffner, 2002 и др.]. Политический дискурс характеризуется как дискурс, референтно соотносящийся со значимыми для общества объектами реальной действительности, поскольку он репрезентирует особый тип организации социальных взаимоотношений, при котором происходит циркулирование политически значимых сообщений внутри политических институтов и за их пределами.

Пиар-дискурс, в отличие от политического дискурса, начал привлекать внимание исследователей сравнительно недавно и в основном в смежных с лингвистикой дисциплинах: социологии и политологии. В исследовании О.Ф. Русаковой и В.М. Русакова пиар-дискурс определяется как разновидность профессионального публичного дискурса, деятельность по производству и воспроизводству особого вида властного ресурса, обозначаемого понятием «социетальный капитал». Оно отражает соединение власти утилитарных и символических ценностей с коммуникативной стратегией, направленной на достижение общего коммуникативного блага - согласия, взаимопонимания, мирного согласования притязаний. Социетальный характер пиар-дискурсу придает его прин- 
E.A. Фролова. Референтная ситуация в политическом пиар-дискурсе: особенности конструирования

ципиальная ориентация на формирование в общественном сознании отношений доверия и лояльности к тем или иным социальным институтам, организациям и фирмам, что в итоге приводит к возвышению их имиджа и репутации [Русакова, Русаков, 2008, с. 79].

Следует отметить, что в социологии акцент делается не столько на пиар-дискурсе, сколько на социальном явлении пиар-деятельности как связей с общественностью. При этом, наряду с положительными характеристиками пиар-деятельности, исследователи выделяют и негативные, например диффамации оппонентов - так называемый черный пиар, который широко используется как средство обмана, очернения репутации и пропаганды неподтвержденных сведений о ком-либо или о чем-либо [Лукашенко, Баранов, Демко, 2010; Ньюсом, Крукеберг, 2001].

В современной политологии явление политического пиара активно изучается [Березкина, 1997; Гринберг, 2005; Ольшанский, 2003]. В частности, Д.В. Ольшанский определяет политический пиар как «особый вид политического менеджмента, главной задачей которого является формирование в массовом сознании узнаваемого положительного образа политической организации, партии или отдельного политика» [Ольшанский, 2003, с. 402]. Имидж и репутация политика формируются с помощью активных пиар-мероприятий. Политик должен соответствовать интересам избирателей; слова, манера, тональность выступления, эмоциональная окрашенность в значительной степени определяют успех выступления, формируя располагающий слушателей имидж политика. Основным политологическим понятием при изучении пиара является позиционирование - «создание и поддержание (воспроизводство) понятного социальной аудитории образа, имиджа» [Ольшанский, 2003, с. 211].

Результаты изучения политического жанра методами социологии и политологии могут быть учтены при выявлении языковых характеристик этого сложного явления.

Опираясь на изложенное выше понимание социального феномена пиар-деятельности, мы предлагаем следующее определение политического пиар-дискурса: это особый тип политического дискурса, производимого в публичном коммуникативном пространстве и имеющего особый контент создания имиджа и управления репутацией политика или политической организации, в целях чего в дискурсе конструируется особая репрезентация мира - особая картина мира.

Проиллюстрируем специфику референтной ситуации, лежащей в основе подобной картины мира: замену общественно значимых референтов на персонально значимые. Это наблюдается, в частности, в следующем фрагменте политического дискурса (ответ Б. Обамы на вопрос присутствующего в зале студента во время предвыборной кампании 2012 г.: http:// obamawhitehouse.archives.gov/thepress-office/2012/10/17/remarks-president-andgovernor-romney-second-presidential-debate):

The student (Jeremy): as a 20-year-old college student, all I hear from professors, neighbors, and others is that when I graduate, I'll have little chance to get employment. What can you say to reassure me, but more importantly, my parents, that I will be able to sufficiently support myself after I graduate?

The President: Jeremy, first of all, your future is bright. And the fact that you're making an investment in higher education is critical not just to you, but to the entire Nation. Now, the most important thing we can do is to make sure that we are creating jobs in this country, but not just jobs, good-paying jobs, ones that can support a family.

And what I want to do is build on the 5 million jobs that we've created over the last 30 months in the private sector alone. And there are a bunch of things that we can do to make sure your future is bright.

Number one: I want to build manufacturing jobs in this country again. When Governor Romney said we should let Detroit go bankrupt, I said, we're going to bet on American workers and the American auto industry, and it's come surging back. I want to do that in industries not just in Detroit, but all across the country. And that means we change our Tax Code so we're giving incentives to companies that are investing here in the United States and creating jobs here. It also means we're helping them and small businesses to export all around the world to new markets.

Number two: We've got to make sure that we have the best education system in the world. And the fact that you're going to college is great, but I want everybody to get a great education. And we've worked hard to make sure that student loans are available for 
folks like you. But I also want to make sure that community colleges are offering slots for workers to get retrained for the jobs that are out there right now and the jobs of the future.

Number three: We've got to control our own energy. Not only oil and natural gas, which we've been investing in, but also we've got to make sure we're building the energy sources of the future, not just thinking about next year, but 10 years from now, 20 years from now. That's why we've invested in solar and wind and biofuels, energy-efficient cars.

We've got to reduce our deficit, but we've got to do it in a balanced way, asking the wealthy to pay a little bit more along with cuts so that we can invest in education like yours. And let's take the money that we've been spending on war over the last decade to rebuild America: roads, bridges, schools. We do those things, not only is your future going to be bright, but America's future is going to be bright as well.

Данный пример иллюстрирует высказанное некоторыми исследователями положение о том, что политический дискурс производится не только политиком, но и социальным адресатом [Шейгал, 2000; Chilton, Schaffner, 2002 и др.]. Здесь социальный адресат актуализируется в конкретном адресате - студенте, задающем политику личный вопрос, который в то же время относится к политической сфере, то есть интересует общество в целом, значим для многих людей.

Вопрос студента имеет референтную соотнесенность с реально существующей объективной ситуацией, значимой для него, а именно, он является студентом колледжа и из разговоров окружающих его людей получает информацию о том, что не сможет найти работу по окончании колледжа. В лингвистических терминах этот вопрос можно определить как касающийся конкретной референтной ситуации будущего мира.

Референция - это соотнесенность актуализированных, включенных в речь имен, именных выражений, именных групп или их эквивалентов к объектам действительности; соответственно, референт - это объект внеязыковой действительности, который имеет в виду говорящий [Арутюнова, 1990, с. 411].

Термин «референтная ситуация» мы понимаем вслед за В.И. Карасиком, который постулирует, что исходным моментом для построения модели того или иного фрагмента языковой картины мира является специфичес- кий референт; такие референтные ситуации обозначаются им как аксиогенные (ценностнопорождающие) [Карасик, 2014, с. 65].

Конструируемая в заданном политику вопросе референтная ситуация будущего мира спрашивающего предполагает возможное отсутствие в ней референта employment; данный референт требуется обозначить с точки зрения так называемой аксиомы существования. Эту аксиому среди прочих выделяет Дж. Сёрль, который указывает на то, что не всякое употребление номинативного выражения является референтным по отношению к реальной действительности, поскольку то, к чему производится референция, должно существовать [Сёрль, 1982, с. 179-180].

В любом дискурсе, референтно соотносящимся с будущим миром, аксиома существования не соблюдается, однако в отношении прогнозируемого будущего мира существует уверенность говорящих, что данный референт или референтная ситуация материализуется. Анализируемый пример демонстрирует неуверенность спрашивающего в возможности в будущем найти работу, политик же пытается вселить в него уверенность. Он обращается к студенту по имени и конструирует для него референтную ситуацию его будущего мира, характеризуемую им с помощью дескрипции с мелиоративной семантикой (bright). Эта референтная ситуация обозначается именно как относящаяся к данному спрашивающему (your future is bright). Однако уже в следующем высказывании политик переходит от референта уои к обобщенному референту the entire Nation, а вслед за этим вводит референт we, который относится уже не ко всему американскому народу, но к американской администрации, руководимой данным политиком.

Далее мы наблюдаем смещение точки зрения, переход от референта же к референту I; в целом же точка зрения смещается с объекта социального мира (employment) на администрацию (we), а затем на референт $I$, то есть происходит такое конструирование референтной ситуации, которое сигнализирует о переходе к пиар-дискурсу, поскольку центральными референтами и темами дискурса становятся уже не объекты и явления социального мира, а определенная политическая партия и представляющий ее политик. 
Следует подчеркнуть, что формирование политического дискурса вокруг центральных референтов $I$ и we само по себе не является признаком его превращения в пиар-дискурс. Политический дискурс становится пиар-дискурсом тогда, когда вся референтная ситуация в целом направлена не столько на репрезентацию социального мира, сколько на конструирование имиджа и репутации политика.

Под имиджем политика мы понимаем его специально формируемый в дискурсе положительный образ, включающий в себя ряд качеств; под репутацией политика мы понимаем оценочное мнение о нем социальной общественности. Данное понимание базируется на имеющихся общих определениях имиджа и репутации [Гринберг, 2005; Heath, 2005].

В анализируемом примере политик целенаправленно конструирует свой положительный имидж, в частности, высказывание (we are creating jobs in this country) peфeрентно соотносится с ситуацией социального мира, но политик сразу добавляет, что создаются высокооплачиваемые рабочие места (good-paying jobs), которые могут хорошо обеспечить семью. Это характеристика настоящего мира как мира «хорошего», мира, в котором создаются высокооплачиваемые места именно данной американской администрацией.

Высказывание (I want to build on the 5 million jobs) базируется на второй аксиоме референции Сёрля - аксиоме, согласно которой, если предикат истинен относительно некоторого объекта, то он истинен и для любого, тождественного данному объекта, вне зависимости от того, какие выражения использованы для референции к этому объекту [Сёрль, 1982, с. 179-180]. Заявление о намерении (I want) вполне может быть принято за истинное, благодаря истинности референтного выражения (5 million jobs).

Далее в дискурсе происходит явное конструирование референтной ситуации в отрыве от объективного мира и переход к самопрезентации. Представляется некий будущий мир, в котором есть студент Джереми с прекрасным будущим, поскольку в этом будущем мире будут созданы новые рабочие места. В настоящем же мире политик заявляет о своем желании их создать (I want to build manufacturing jobs in this country). Таким образом, политический дискурс переводится из модуса реального существования в модус желания (подробно о таком переносе см.: [Арутюнова, 1999, с. 411]), что свидетельствует, на наш взгляд, об использовании говорящим стратегии самопрезентации, предъявления к восприятию своих положительных качеств.

Переход к самопрезентации наблюдается, в частности, при конструировании референтной ситуации «прошлого» мира (When Governor Romney said we should let Detroit go bankrupt, I said, we're going to bet on American workers and the American auto industry, and it's come surging back. I want to do that in industries not just in Detroit, but all across the country).

Ситуация, имевшая место в прошлом (дебаты между представителями двух партий), конструируется не с точки зрения значимых объектов реальной действительности (Detroit, the American auto industry, American workers) и острых социальных проблем, с ними связанных, а с точки зрения лучшего ответа оппоненту (When Governor Romney said - I said) и желания (I want). Это свидетельствует не об интенции решения социальных вопросов, а, скорее, об интенции представить себя как выигравшего в тех дебатах и как победителя в целом, а также как политика, желающего блага народу.

Личностное качество «политик, желающий блага народу» является в данном дискурсе основным самомоделируемым положительным качеством имиджа: выражение (I want) повторяется в ответе Б. Обамы 5 раз. Его употребление носит пронизывающий характер; оно интегрирует контент дискурса, превращая его в пиар-дискурс.

Конструируемый политиком будущий мир - это не только мир, желаемый им, но также мир «должного», на что указывает сквозное употребление конструкции we've got to (we've got to make sure that we have the best education system in the world; we've got to control our own energy; we've got to make sure we're building the energy sources of the future; we've got to reduce our deficit; we've got to do it in a balanced way). В данном случае референтная соотнесенность местоиме- 


\section{МАТЕРИАЛЫ И СООБЩЕНИЯ}

ния we с объектами мира неясна: неясно, кто должен осуществить все перечисленное. Однако совершенно прозрачна связь референтов we и $I$, выражающая единство политика с народом, его самомоделируемое качество «политик, заботящийся о будущем народа».

Мы можем охарактеризовать такой дискурс как дискурс конструирования другого, возможного мира [Плотникова, 2014], а не только как порождение версии реальности, выгодной политику.

Находясь в реальном времени и пространстве, политик создает в своем дискурсе будущий, желаемый мир, в котором Америку ожидает прекрасное будущее (America's future is going to be bright). Конструируя особую картину мира, он трансформирует картину реального, действительного мира, инкорпорируя в него свою точку зрения на изменения, которые должны произойти в будущем.

Переход от политического дискурса к политическому пиар-дискурсу объективируется и в структурных терминах. Пиар-дискурс оформляется в виде отдельного структурного образования. Его началом является высказывание с мелиоративной семантикой (уоur future is bright), которое повторяется с использованием инверсии в конце дискурса (not only is your future going to be bright, but America's future is going to be bright as well). Это создает рамочную конструкцию для референтной ситуации, в которой главными референтами и темами дискурса становятся уже не объекты и явления социального мира, а имидж и репутация определенной политической партии и представляющего ее политика.

3

Итак, политический пиар-дискурс является одним из видов гибридного дискурса, в котором происходит наложение и взаимопроникновение специфических характеристик политического дискурса и пиар-дискурса, благодаря чему формируются общие структурные свойства политического пиар-дискурса как единого целого. Дискурс остается политическим, поскольку его основная цель - решение какой-либо текущей политической задачи (победа на выборах, привлечение новых сторонников и т. д.). Пиар-компонент лишь модифицирует структуру и содержание политического дискурса.

Вместе с тем гибридизация не является простым инкорпорированием одного дискурса в другой, поскольку дискурсы не присоединяются друг к другу в виде отдельных самостоятельных фрагментов текста. Политический пиар-дискурс представляет собой гомогенное образование благодаря тому, что в его основе лежит единая референтная ситуация, включающая как референты, относящиеся к текущей политической ситуации, так и референты, характеризующие ситуацию самопрезентации положительного имиджа политика, когда дискурсивизируются его сугубо позитивные личностные качества.

Конструирование референтной ситуации в политическом пиар-дискурсе происходит в отрыве от объективного социального мира; конструируется некий будущий, желаемый мир. Основой для конструирования референтной ситуации желаемого мира служат референты, допускающие ценностное осмысление. Референтная ситуация, в связи с этим, является аксиогенной; в качестве ценностных доминант в ней конструируются имидж и репутация политика. Ценностно маркированная референтная ситуация репрезентирует мир в аспекте его индивидуального видения конкретным политиком. Конструирование референтной ситуации направлено на формирование в социуме позитивного отношения к данному политику; на языковом уровне оно объективируется с помощью мелиоративной семантики используемых политиком слов и высказываний.

На наш взгляд, изучение лингвистических особенностей феномена самопрезентации политика через использование пиар-компонента в политическом дискурсе позволяет углубить научное знание о современных тенденциях развития политического дискурса.

\section{СПИСОК ЛИТЕРАТУРЫ}

Арутюнова Н. Д., 1990. Референция // Лингвистический энциклопедический словарь / под ред. В. Н. Ярцевой. М. : Советская энциклопедия. C. 411 .

Арутюнова Н. Д., 1999. Язык и мир человека. М. : Языки русской культуры. 905 с. 
Березкина О. П., 1997. Социально-психологические технологии создания политического имиджа. СПб. : Изд-во СПбГУ. 324 с.

Гринберг Т. Э., 2005. Политические технологии: пиар и реклама. М. : Аспект Пресс. 317 с.

Ирисханова О. К., 2011. Гибриды - экзотика или универсальные ингредиенты семиотических систем? // Семиотическая гетерогенность языковой коммуникации: теория и практика. Тезисы докладов Междунар. науч. конф. (МГЛУ, 27-28 октября 2011 г.). М. : Рема. С. 62-63.

Карасик В. И., 2014. Аксиогенная ситуация как единица ценностной картины мира // Политическая лингвистика. № 1 (47). С. 65-75.

Лукашенко М. А., Баранов Д. Е., Демко Е. В., 2010. PR: теория и практика / под ред. М. А. Лукашенко. М. : Маркет ДС. 328 с.

Ньюсом Д., Крукеберг Д., 2001. Bсе о PR: теория и практика паблик рилейшнз. М. : ИНФРА-М. $624 \mathrm{c}$.

Ольшанский Д. В., 2003. Политический PR. СПб. : Питер. 544 с.

Панченко Н. Н., 2011. Интенциональный характер инкорпорирования комического в английском новостном дискурсе // Magister Dixit. № 2. C. $192-197$.

Плотникова С. Н., 2003. Комический дискурс // Аксиологическая лингвистика: игровое и комическое в общении : сб. науч. тр. / под ред. В. И. Карасика, Г. Г. Слышкина. Волгоград : Перемена. С. 162-172.

Плотникова С. Н., 2004. Самомоделирование личности политика как дискурсивная технология // Политический дискурс в России - 7. Образы без лиц : материалы постоянно действующего семинара / под ред. В. Н. Базылева и В. Г. Красильниковой. М. : МАКС Пресс. C. $50-54$.

Плотникова С. Н., 2005. Политик как конструктор дискурса реагирования // Политический дискурс в России - 8. Святые без житий. М. : МАКС Пресс. С. 22-26.

Плотникова С. Н., 2014. Дискурсивное конструирование как теоретическое понятие // Известия Волгоградского государственного педагогического университета. № 5 (90). С. 41-46.

Русакова О. Ф., Русаков В. М., 2008. PR-дискурс: Теоретико-методологический анализ. Екатеринбург : Институт философии и права УрО РАН, Институт международных связей. 282 с.

Сёрль Дж. Р., 1982. Референция как речевой акт // Новое в зарубежной лингвистике. Вып. 13. Логика и лингвистика (Проблемы референции). М. : Радуга. С. 179-202.

Чудинов А. П., 2006. Политическая лингвистика. М. : Флинта : Наука. 256 с.
Шейгал Е. И., 2000. Семиотика политического дискурса. Волгоград : Перемена. 368 с.

Chilton P., Schaffner C., 2002. Politics as Text and Talk: Analytical Approaches to Political Discourse. Amsterdam : Benjamins. 245 p.

Heath R. L., 2005. Encyclopedia of public relations. London: Sage Publications Ltd. 1101 p.

\section{REFERENCES}

Arutyunova N.D., 1990. References. Linguistic encyclopedic dictionary. Moscow, Soviet encyclopedia Publ. 411 p. (in Russian).

Arutyunova N.D., 1999. Language and the world of the person. Moscow, Yazyki russkoy kultury Publ. 905 p. (in Russian).

Berezkina O.P., 1997. Social and psychological technologies of creation of political image. Saint Petersburg. 285 p. (in Russian).

Grinberg T.E., 2005. Political technologies: PR and advertizing. Moscow, Aspekt Press. 317 p. (in Russian).

Iriskhanova O.K., 2011. Hybrids - exotic or universal ingredients of semiotics systems? Semioticheskaya geterogennost yazykovoy kommunikatsii: teoriya i praktika. Tezisy dokladov Mezhdunar. nauchn. konf. (MSLU, 27-28 October 2011) [Semiotic heterogeneity of language communication: theory and practice. Theses of reports of Int. sci. conf., MSLU, 27-28 october, 2011]. Moscow, Rema Publ., pp. 62-63. (in Russian).

Karasik V.I., 2014. Axiogenic situation as a unit of the value worldview. Politicheskaya lingvistika. [Political Linguistics Journal], no. 1 (47), pp. 6575. (in Russian).

Lukashenko M.A., Baranov D.E., Demko E.V., 2010. PR: theory and practice. Moscow, Market DS. 328 p. (in Russian).

Nyusom D., Krukeberg D., 2001. In total about PR: theory and practice of public relations. Moscow, INFRA-M Publ. 624 p. (in Russian).

Olshanskiy D.V., 2003. Political PR. Saint Petersburg, Piter. 544 p. (in Russian).

Panchenko N.N., 2011. The intentional nature of incorporation of the comic in English news discourse. Magister Dixit, no. 2, pp. 192-197. (in Russian).

Plotnikova S.N., 2003. Comic discourse. Karasik V.I., Slyshkin G.G., eds. Aksiologicheskaya lingvistika: igrovoe i komicheskoe v obshchenii: Sb. nauch. tr. [Axiological linguistics: linguistic play and comic commentaries in communication. Coll. of sci. works]. Volgograd, Peremena Publ., pp. 162-172. (in Russian). 


\section{МАТЕРИАЛЫ И СООБЩЕНИЯ}

Plotnikova S.N., 2004. Self-modeling of the identity of the politician as a discoursive technology. Politicheskiy diskurs $v$ Rossii-7. Obrazy bez lits: materialy postoyanno deystvuyushchego seminara [Political discourse in Russia - 7 . Images without persons: mat. of a perm. seminar]. Moscow, MAKS Press, pp. 50-54. (in Russian).

Plotnikova S.N., 2005. Politician as a constructor of a reaction discourse. Politicheskiy diskurs $v$ Rossii-8. Svyatye bez zhitiy [Political discourse in Russia - 8. Saints without lives]. Moscow, MAKS Press, pp. 22-26. (in Russian).

Plotnikova S.N., 2014. Discursive construction as a theoretical concept. Izvestiya Volgogradskogo gosudarstvennogo pedagogicheskogo universiteta. Ser. Filologicheskie nauki [Izvestia of the Volgograd State Pedagogical University], no. 5 (90), pp. 41-46. (in Russian).
Rusakova O.F., Rusakov V.M., 2008. PR-Discourse: Theoretical and methodological analysis. Ekaterinburg, Institut filosofii i prava UrO RAN, Institut mezhdunarodnyh svyazey. 282 p. (in Russian).

Serl Dzh.R., 1982. Reference as a speech act. Novoe v zarubezhnoy lingvistike. Vyp. 13. Logika $i$ lingvistika (Problemy referentsii) [New trends in foreign linguistics. Vol. 13. The logic and linguistics (Problems of references)]. Moscow, Raduga Publ., pp. 179-202. (in Russian).

Chudinov A.P., 2006. Political linguistics. Moscow, Flinta, Nauka Publ. 256 p. (in Russian).

Sheygal E.I., 2000. Semiotics of political discourse. Volgograd, Peremena Publ. 368 p. (in Russian).

Chilton P., Schaffner, 2002. Politics as Text and Talk: Analytical Approaches to Political Discourse. Amsterdam, Benjamins. 245 p.

Heath R.L., 2005. Encyclopedia of public relations. London, Sage Publications Ltd. 1101 p.

\section{Information about the Author}

Evgeniya A. Frolova, Postgraduate Student, Department of English Philology, Irkutsk State University, Karla Marksa St., 1, 664003 Irkutsk, Russia, goldentress@mail.ru, http://orcid.org/0000-00026452-1353

\section{Информация об авторе}

Евгения Александровна Фролова, аспирант кафедры английской филологии, Иркутский государственный университет, ул. Карла Маркса, 1, 664003 Иркутск, Россия, goldentress@mail.ru, http://orcid.org/0000-0002-6452-1353 